\title{
Anaemia in Patients on Haemodialysis Therapy in Dar es Salaam, Tanzania
}

\author{
Ruggajo $\mathrm{P}^{1-3}$, Shoo May ${ }^{1}$, Jonathan $\mathrm{I}^{1, *}$, Mngumi J $\mathrm{J}^{2}$, Fredrick $\mathrm{F}^{2,4}$, Chillo $\mathrm{P}^{1,3}$, and Kamuhabwa $\mathrm{A}^{3}$ \\ ${ }^{1}$ Department of Internal Medicine, Dar es Salaam, Tanzania \\ ${ }^{2}$ Renal Research Group, MUHAS/MNH, Dar es Salaam, Tanzania \\ ${ }^{3}$ Non-Communicable Diseases Research Writing Group, MUHAS, Dar es Salaam, Tanzania \\ ${ }^{4}$ Department of Paediatrics and Child Health, MUHAS, Dar es Salaam, Tanzania
}

*Corresponding author: Jonathan I, Department of Internal Medicine, Dar es Salaam, Tanzania, Tel: +255620 704927 /+255653 717059; E-mail: rinnybella@gmail.com

Received: 06 Aug, 2019 | Accepted: 29 Aug, 2019 | Published: 05 Sep, 2019

Citation: Ruggajo P, May S, Jonathan I, Mngumi J, Fredrick F, et al. (2019) Anaemia in Patients on Haemodialysis Therapy in Dar es Salaam, Tanzania. Int J Nephrol Kidney Fail 5(4): dx.doi.org/10.16966/2380-5498.181

Copyright: (c) 2019 Ruggajo P, et al. This is an open-access article distributed under the terms of the Creative Commons Attribution License, which permits unrestricted use, distribution, and reproduction in any medium, provided the original author and source are credited.

\section{Abstract}

Background: Anaemia is a common complication among patients with End Stage Renal Disease (ESRD) on Maintenance Haemodialysis Therapy (MHD) and is associated with increased morbidity and mortality. The aim of this study was to determine the prevalence of anaemia and associated factors among patients on maintenance haemodialysis in Dar es Salaam, Tanzania.

Material and Methods: A total of 233 patients receiving Maintenance Haemodialysis Therapy (MHD) from three centers in Dar es Salaam, Tanzania between September and October 2017 were recruited into this study. Data was analyzed using SPSS version 23 software and summarized into frequency tables. Log binomial regression analysis was used to estimate relative risks and determine factors associated with anaemia.

Results: A total of 233 participants ( $65 \%$ male) were recruited into the study. Over three quarters (78\%) of the patients were aged 40 years or more with overall mean Haemoglobin $(\mathrm{Hb})$ level of $11 \mathrm{~g} / \mathrm{dl}$. The overall prevalence of anaemia was $69 \%$, stratified by gender $74 \%$ of female and $64 \%$ of male patients had anaemia $(\mathrm{Hb}<12 \mathrm{~g} / \mathrm{dl}$ for female and $<13 \mathrm{~g} / \mathrm{dl}$ for male gender) respectively, the observed difference between gender was not statistically significant $(p=0.26)$. Stratified by underlying cause of anaemia, $84 \%$ were attributed to serum iron deficiency, $0.43 \%$ to serum folate deficiency and none to serum vitamin B12 deficiency respectively. In the multivariate analysis; low serum transferrin saturation $<30 \%$ [AOR 9.29 , $95 \% \mathrm{Cl}(4.15-20.80), p<0.001$ ] and presence of more than one comorbidity [AOR 1.89 (1.04-3.49), $p=0.04$ ] were independently associated with anaemia. Conversely, being educated beyond primary level education [AOR $0.37(0.19-0.76), p=0.006$ ] and being on hemodialysis for more than 1 year [AOR $0.4(0.21-0.80), p=0.01]$ were found to be protective against anaemia in these patients.

Conclusion: High prevalence of anaemia (especially Iron Deficiency Anaemia) was found in patients receiving maintenance hemodialysis for end stage renal disease in Dar es Salaam Tanzania. Presence of more than one comorbidity and low serum transferrin saturation were associated with anaemia whereas post primary school education and receiving hemodialysis therapy for more than one year seemed to confer protection against anaemia in these patients.

Keywords: Anaemia; Maintenance Haemodialysis; Associated Factors; Tanzania

\section{Introduction}

Anaemia is defined as the state in which the quality and/or quantity of circulating blood cells is below normal or the established cut off defined by the World Health Organization (WHO 2001). And according to the standards of International Society of Nephrology, namely Kidney Disease Improving Global Outcomes (KDIGO) is defined as having haemoglobin level below $12 \mathrm{~g} / \mathrm{dl}$ for female and 13 $\mathrm{g} / \mathrm{dl}$ for male. Anaemia is a common complication among patients on Maintenance Hemodialysis (MHD) due to End Stage Renal Disease (ESRD), and its occurrence underlies some of the symptoms associated with reduced kidney function, including fatigue, depression, reduced exercise tolerance, and dyspnoea [1].
Moreover, anaemia has been linked with worse clinical outcomes such as increased morbidity and mortality due to cardiovascular disease [2]. This complication increases the risk of hospitalization and length of hospital stay and therefore dramatically reducing the quality of life of these patients [3-5]. End Stage Renal Disease is characterized by nutritional impairment, anaemia, hypertension, renal bone disease, neuropathy, nutritional impairment, and reduced life expectancy [6,7]. Anaemia worsens with progressive kidney disease implicating multiple factors being related to its etiology including inability of the failing kidneys to secrete the hormone erythropoietin, uremic toxins and excess aluminum accumulation on bone marrow of patients on long term dialysis, blood loss, increased red blood cell destruction and altered platelet function due to uremia among others [8]. 
Previous studies have reported high prevalence of anaemia (85\% in Iran and $94.3 \%$ in Cameroon) among patients on maintenance hemodialysis therapy and several associated factors have been implicated including being on hemodialysis for a long duration (1-5 years) $[9,10]$. Anaemia secondary to serum vitamin B12 and folate deficiency is associated with increased mortality in incident haemodialysis [11]. Further, it has been reported that chronic dialysis, poor appetite and decreased food intake due to advanced uremia all contribute to deficiency of these important vitamins [12]. Both absolute and functional iron deficiency have been considered to be important causes of anaemia in ESRD patients undergoing maintenance hemodialysis therapy [13]. In these patients, (absolute) iron stores are depleted as a result of decreased intake due to malnutrition and decreased appetite associated with uremia as well as increased blood loss through chronic gastrointestinal tract bleeding secondary to increased blood vessel fragility, platelet dysfunction and chronic blood retention in the dialysis circuit [14]. Functional Iron Deficiency (FID) occurs when there is increased demand (than the amount that can be released from the stores) to support hemoglobin synthesis. A previous study has reported the prevalence of FID to be as high as $21 \%$ and this was associated with high levels of hepcidin and inflammatory markers [15]. In particular, ESRD patients have impaired release of stored iron from macrophages and hepatocytes to transferrin [14].Literature is still scanty on the contribution of acute blood loss from hemodialysis vascular access as a significant cause of anaemia among patients on MHD. Temporary vascular catheters used in hemodialysis (jugular and femoral catheters) are known to indirectly contribute to anaemia by promoting frequent bacterial infection related to catheter, which in turn is associated with frequent hemolysis culminating into anaemia among these patients $[16,17]$.

In Tanzania as a model setting for the wider WHO sub-saharan region, maintenance hemodialysis therapy has been offered to ESRD patients for over a decade now, however, there are no published information magnitude, characterization and exploration of associated factors in our settings. The aim of this study is to investigate the magnitude of anaemia and its associated factors among patients on MHD in Dar es Salaam, Tanzania.

\section{Materials and Methods}

\section{Study design, population and settings}

This was a descriptive cross sectional study that involved consecutive recruitment of ESRD patients on MHD among three HD centres (Muhimbili National Hospital, Access Dialysis Centre and TMJ Hospital) all located in Dar es Salaam City, Tanzania.

\section{Inclusion criteria}

All patients aged 18 years and above, diagnosed with ESRD on MHD were included in the study.

\section{Exclusion criteria}

All patients with ESRD on MHD who received blood transfusion within 2 weeks.

\section{Dependent variable}

In this study, anaemia was measured as binary outcome i.e. those who were anaemic $v s$ those without. Anaemia was defined according to the standards of International Society of Nephrology, namely Kidney Disease Improving Global Outcomes (KDIGO). According to the KDIGO classifications, anaemia was defined as hemoglobin level below $12 \mathrm{~g} / \mathrm{dl}$ for female and $13 \mathrm{~g} / \mathrm{dl}$ for male gender.

\section{Independent variables}

The patient sociodemographic and clinical characteristics including age, gender, presence of co-morbidities (diabetes mellitus, hypertension, HIV disease, liver disease, hepatitis B\&C infection, malignancies, cerebral vascular event and heart disease.), types of vascular accesses used for hemodialysis (temporary $v s$. permanent access); and serum levels of folate, Vitamin B12 and iron were all recorded.

\section{Data collection and laboratory procedures}

A total of 233 patients who met inclusion criteria were recruited into our study. Sociodemographic and clinical data was collected using a structured Swahili questionnaire (after translating into and back translated from English). Venipunctures were aseptically performed to every recruited study participant and $4 \mathrm{mls}$ of blood were collected into sterile EDTA bottle and analysed for haematological parameters; $10 \mathrm{mls}$ of blood were collected from each participant using red top bottle and analysed for serum iron, vitamin B12 and folate levels. Additional information (including haemoglobin level) was extracted from patients' medical files.

\section{Data analysis}

Data collected were entered into pre-developed data entry screens using EPIDATA version 3.02 for cleaning and data analysis was performed using SPSS version 23 software. Statistical means with standard deviation and proportions were used to summarize continuous data and categorical data respectively. The correlation between anaemia and different parameters was determined by performing logistic regression analyses. Odds ratios (OR) were calculated to estimate the risk associated with anaemia development. A two-tailed cut-off at $\mathrm{p}$-value $<0.05$ was considered to be statistically significant.

\section{Ethical Consideration}

The study was approved by the Research and Publication Committee of Muhimbili University of Health and Allies Sciences (MUHAS) and Ethical Committees of the three participating hospitals.

\section{Results}

\section{Demographic and clinical characteristics of study participants}

A total of 233 patients with ESRD were enrolled. Proportionally, these patients were distributed in the three dialysis centers as follows; Muhimbili National Hospital (37\%), TMJ Hospital (29\%) and Access Dialysis Centre (34\%). About two-thirds (65.2\%) of patients were male. The mean $( \pm \mathrm{SD})$ age was $51.4 \pm 14.2$ years and majority $(65.3 \%)$ had received at least primary school level education. The mean hemoglobin levels of the study participants were $11 \pm 2 \mathrm{~g} / \mathrm{dl}$ (Table 1$)$.

\section{Prevalence of Anaemia among patients on MHD}

Of the 233 participants, 161 (69\%) were found to be anemic. Proportionally, male patients were more anemic than female but the observed difference was not statistically significant $(43 \%$ vs. $26 \%$, p-value 0.249) (Figure 1).

Proportion of Patients on MHD with Iron Deficiency Anaemia ( $\mathrm{N}=233$ participants)

Majority of the study participants 195/233 (84\%) had Iron Deficiency Anaemia (IDA) (Figure 2). 


\section{Proportion of patients with Vitamin B12 and Folate deficiency among study participants}

Only 1 patient among 233 patients (0.43\%) had folate deficiency and none had vitamin B12 deficiency.

\section{Factors associated with developing anaemia among ESRD patients on MHD}

Socio-demographic and clinical factors: Patients who had two or more co-morbidities were more likely to be anaemic than those who had only one co-morbidity ( $\mathrm{OR}=2.02$; $95 \% \mathrm{CI}: 1.152-3.569$; $\mathrm{p}<0.05)$. Odds of being anaemic was $43 \%$ less in those who have been on dialysis therapy for more than one year as compared with those who have been on treatment for less than 1 year. Patients with education level beyond primary school had less likelihood of developing anaemia compared to those who attained lower education levels $(\mathrm{AOR}=0.37$; 95\% CI: 0.187-0.761; $\mathrm{p}<0.05$ ) (Table 2).

Clinic laboratory measurement association with anaemia among study participants: While low transferrin saturation was significantly associated with anaemia ( $\mathrm{OR}=9.29 ; 95 \% \mathrm{CI}$ : 4.15-20.80; $\mathrm{p}<0.001)$, the association with other laboratory and clinical parameters was not statistically significant (Table 3 ).

\section{Discussion and Conclusion}

The present study was done to determine the prevalence of anaemia among patients with ESRD on MHD and its associated factors. We found a high prevalence of anaemia among these patients (69\%), with iron deficiency being the predominant type. Furthermore, having more than one co-morbidities and a low transferrin saturation was significantly associated with anaemia. Conversely, we found that level of education beyond primary education, duration of dialysis therapy beyond one year and permanent vascular access were shown to be protective against anaemia in these patients.

Table 1: Demographic and Clinical Characteristics of ESRD Patients on MHD in Dar es Salaam ( $\mathrm{N}=233$ ).

\begin{tabular}{|l|c|c|}
\hline \multicolumn{1}{|c|}{ Characteristic } & $\mathbf{n}$ & $\%$ \\
\hline Age in years(mean \pm SD) & $51.41 \pm 14.21$ & \\
\hline Sex & & \\
\hline Male & 152 & 65.2 \\
\hline Female & 81 & 34.8 \\
\hline Marital status & & \\
\hline Single & 33 & 14.2 \\
\hline Living with partner & 200 & 85.8 \\
\hline Education level & & \\
\hline Primary and below & 81 & 34.7 \\
\hline Above primary & 152 & 65.3 \\
\hline Treatment facility & & \\
\hline Muhimbili & 86 & 36.9 \\
\hline TMJ & 67 & 28.8 \\
\hline Access & 80 & 34.3 \\
\hline Co-morbidity* & 111 & \\
\hline One & 122 & \\
\hline More than one & Mean \pm SD & \\
\hline Hemogram parameters & $11 \pm 2$ & \\
\hline Hemoglobin level (g/dl) & & \\
\hline
\end{tabular}

*Comorbidities defined as having ESRD together with any of the following; diabetes, hypertension, HIV disease, liver disease, hepatitis B \& C infection, malignancies, cerebrovascular event, heart disease.
In this study, male gender and individuals aged 40-59 years were the majority comprising $61 \%$ and $41 \%$ of the study participants respectively. Comparable results on association between male gender and ESRD have also been reported by studies done in Cameroon and Brazil $[18,19]$. High proportion of male patients might at least in part, be explained by the fact that males are more prone to hypertension and diabetes mellitus which are the major comorbidities associated with ESRD [20,21].

The prevalence of anaemia of $69 \%$ found in this study, is comparable to that reported from previous reports which show a prevalence between 67.4 and $75.5 \%[22,23]$. However, there are few studies which showed a very high prevalence of $96.5 \%$ [24]. As expected high prevalence of anaemia in these patients could be due to increased iron losses, chronic bleeding from uremia-associated platelets dysfunction, frequent phlebotomy and blood trapping in the dialysis apparatus [25]. The anaemia may also be secondary to impaired oral iron absorption.

Majority (84\%) of study participants had iron deficiency anaemia. This finding was similar to previous studies which showed iron deficiency as the commonest type of anaemia in patients with ESRD

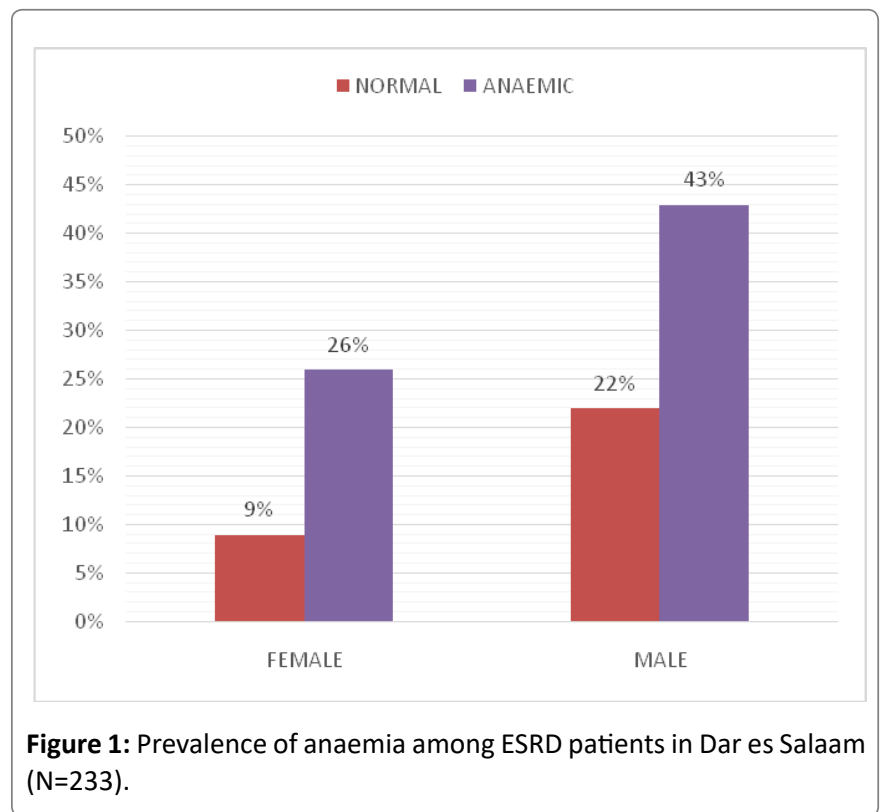
$(\mathrm{N}=233)$.

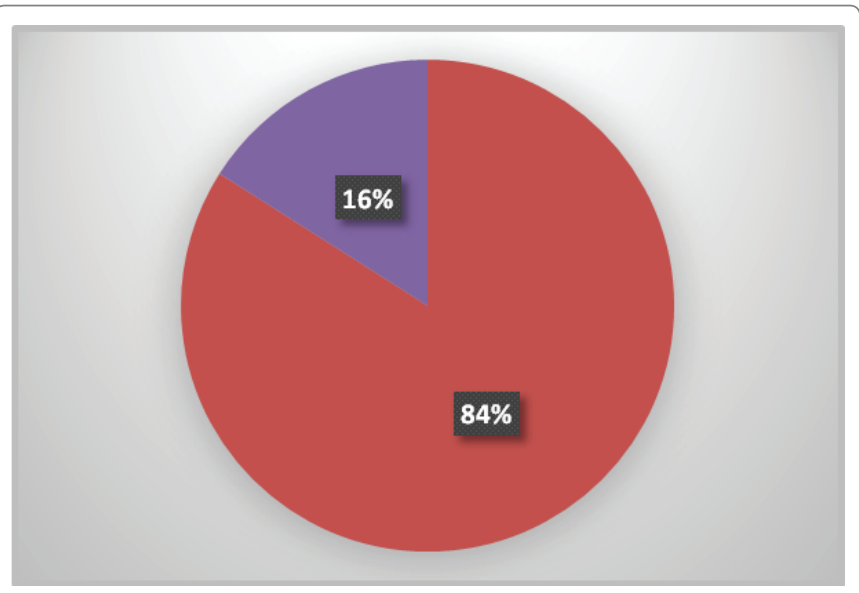

Figure 2: Prevalence of Iron Deficiency among study participants. 
Table 2: Factors associated with Anaemia among ESRD patients on MHD in Dar es Salaam (N=233).

\begin{tabular}{|c|c|c|c|c|c|c|c|}
\hline Factor & Anaemia Yes, n (\%) & Crude OR & $95 \% \mathrm{Cl}$ & p-value & AOR & $95 \% \mathrm{Cl}$ & p-value \\
\hline \multicolumn{8}{|c|}{ Gender } \\
\hline Male & $101(66.4)$ & Ref & & & Ref & & \\
\hline Female & $60(74.1)$ & 1.44 & 0.792 .63 & 0.231 & 1.47 & $0.76-2.82$ & 0.249 \\
\hline \multicolumn{8}{|c|}{ Education level } \\
\hline Primary or below & $66(81.5)$ & Ref & & & Ref & & \\
\hline Beyond primary & $95(62.5)$ & 0.78 & $0.46-1.35$ & 0.392 & 0.37 & $0.19-0.76$ & 0.006 \\
\hline \multicolumn{8}{|c|}{ Dialysis duration } \\
\hline$<1$ year & $86(78.2)$ & Ref & $0.24-0.78$ & & Ref & & \\
\hline$\geq 1$ year & $75(60.9)$ & 0.43 & & 0.005 & 0.4 & $0.21-0.80$ & 0.012 \\
\hline \multicolumn{8}{|c|}{ Co-morbidity } \\
\hline One & $68(61.3)$ & Ref & & & Ref & & \\
\hline 2 or more & $93(76.3)$ & 2.02 & $1.15-3.57$ & 0.014 & 1.89 & $1.04-3.49$ & 0.038 \\
\hline \multicolumn{8}{|c|}{ Dialysis access } \\
\hline Temporary Catheter & $42(78.2)$ & Ref & & & Ref & & \\
\hline Permanent Catheter & 119(67.6) & 0.74 & $0.38-1.45$ & 0.39 & 0.75 & $0.34-1.65$ & 0.476 \\
\hline
\end{tabular}

* Comorbidities defined as having ESRD together with any of the following; diabetes, hypertension, HIV disease, liver disease, hepatitis B \& C infection, malignancies, cerebrovascular event, heart disease.

Table 3: Clinicolaboratory factors associated with Anaemia among ESRD patients on MHD in Dar es Salaam (N=233).

\begin{tabular}{|c|c|c|c|c|c|c|c|}
\hline Factor & $\begin{array}{c}\text { Anaemia } \\
\text { n (\%) }\end{array}$ & $\begin{array}{c}\text { Crude } \\
\text { OR }\end{array}$ & $95 \% \mathrm{Cl}$ & p-value & AOR & $95 \% \mathrm{Cl}$ & p-value \\
\hline \multicolumn{8}{|c|}{ White Blood Cell Count (10\%/L) } \\
\hline 4-11 & $136(66.6)$ & & & & Ref & & \\
\hline$>11$ & $25(86.2)$ & 3.13 & $1.05-9.34$ & 0.002 & 2.26 & $0.69-7.46$ & 0.179 \\
\hline \multicolumn{8}{|c|}{ Random Blood Sugar level(mmol/I) } \\
\hline $4-7$ & $123(66.1)$ & Ref & & & Ref & & \\
\hline$>7$ & $38(80.8)$ & 2.16 & $0.98-4.75$ & 0.05 & 1.94 & $0.80-4.70$ & 1.4 \\
\hline \multicolumn{8}{|c|}{ Systolic Blood pressure(mmHg) } \\
\hline $120-139$ & $54(62.7)$ & Ref & & & Ref & & \\
\hline$\geq 140$ & $107(72.8)$ & 1.58 & $0.86-2.79$ & 0.155 & & & \\
\hline \multicolumn{8}{|c|}{ Diastolic blood pressure $(\mathrm{mmHg})$} \\
\hline $80-89$ & 121(69.1) & Ref & & & & & \\
\hline$\geq 90$ & $40(68.9)$ & 1.56 & $0.86-2.85$ & 0.141 & & & \\
\hline \multicolumn{8}{|c|}{ Transferrin saturation (\%) } \\
\hline $30-50$ & $10(26.3)$ & Ref & & & Ref & & \\
\hline$<30$ & $151(77.4)$ & 1.37 & $1.73-2.62$ & $0<0.001$ & 9.29 & $4.15-20.80$ & $<0.001$ \\
\hline
\end{tabular}

[26,27]. High iron deficiency anaemia can be explained by similar mechanisms as reported previously by Jodie and colleagues as well as that reported by Allan, et al. that proposed that iron stores are depleted in patients with ESRD as a result of decreased intake due to decreased appetite, increased loss through chronic gastrointestinal bleeding secondary to increased blood vessel fragility, platelet dysfunction related to uremia, and disordered iron homeostasis as a result of hepcidin excess which impairs dietary iron absorption and iron mobilization from body stores [28,29]. Additionally, this could also be due to low usage status of Erythropoietin (EPO) injection in our setting, whereby anecdotal data from Muhimbili National Hospital main pharmacy shows that by the end of July 2019, only $48.9 \%$ of ESRD patients on MHD were on EPO therapy.

We also found that the prevalence of anaemia was higher (86.2\%) among patients with raised white cell count that is considered as a crude surrogate marker for infection in this study. However, there was no statistical significance of the above finding $(\mathrm{p}=0.179)$. Similar findings have been reported in a study by Peter in 2001 [30] and an 
article by Kwaan $\mathrm{HC}$ on infection and anaemia [31]. Another study by Roberts TL, et al. also found an association between vascular access infections and anaemia in hemodialysis patients [32]. Abnormal white blood cells and anaemia is caused by raised pro-inflammatory cytokine which brings bone marrow suppression of erythropoiesis, reduced erythropoietin secretion, intestinal bleeding and disruption of iron metabolism [17]. The infection can also potentiate hemolysis of red blood cells leading to anaemia.

Contrary to what has been reported from other studies, our study found that anaemia was more prevalent among patients who had been on MHD for a shorter duration (less than 1 year). A study done in Cameroon for instance, found that longer duration of hemodialysis (1-5 years) was associated with a relatively higher prevalence of anaemia $(54.5 \%$ vs $30.3 \%)$ compared to patients who have been on hemodialysis for less than a year [4]. We hypothesize that the association between short duration of hemodialysis and anaemia observed in this present study could be explained by the fact that patients on hemodialysis for less than one year might have not yet received an optimal composite dose of adequate dialysis, oral iron supplements and EPO therapy (all of which decrease the risk for anaemia) compared to those who are on dialysis for at least one year.

We also found that ESRD patients with more than one co-morbidity were significantly two fold more likely to have anaemia compared to those with one comorbidity (OR=2.02; 95\% CI: 1.152-3.569; $\mathrm{p}<0.05)$. In a separate analysis, a $\mathrm{p}$ for trend association was also evident between diabetes mellitus and anaemia in ESRD. These findings are consistent with a large scale cross sectional multi survey study conducted in the US that revealed a correlation between diabetes mellitus and anaemia [33] and another study that found a strong association between diabetes and anaemia among $C K D$ patients $(\mathrm{OR}=2.31$; $\mathrm{p}$-value 0.005$)$ [34]. This can be explained by the tubulointerstitial damage that occurs in patients with diabetes mellitus correlating with decrease in functional renal tissue and resultant decrease in EPO production in response to hypoxia in the kidney [35]. Furthermore, systemic inflammation associated with microvascular disease in patients with diabetes leads to the production of inflammatory mediators, such as interleukins and tissue necrosis factor, these mediators blunt the effect of erythropoietin on the bone marrow, where erythroid precursors are stimulated contributing further to anaemia in these patients [36].

We also found that a greater proportion of patients with temporary vascular access (femoral/jugular venous catheters) had high propensity of getting anaemia compared to those with permanent vascular access. Similar findings were reported by a study conducted by Roberts TL, et al. on the relationship among catheter insertions, vascular access infections, and anaemia management in haemodialysis patients which showed that patients with temporary vascular access may have higher rates of anaemia, and require greater doses of intravenous iron and recombinant human EPO compared with patients with permanent vascular accesses [32]. This is because temporary vascular catheters cause anaemia indirectly by increasing the risk of infection which can lead to hemolysis of red blood cells culminating into anaemia [3739]. This can also be supported by results of a manuscript in print on bacteremia in patients on HD therapy in Dar es Salaam, which showed that the proportion of patients with temporary vascular access who had bacteremia was high compared to those with permanent vascular access $(38.7 \%$ and $18.8 \%)$ respectively.

The strengths of this study include the fact that the study is representative of a wider sub-saharan region where publications carrying such information is rare. However, the fact that the study was done only in one city may limit its generalization in representing the whole country. We suggest more comprehensive studies with bigger sample sizes representing a wider geographical area.

In conclusion, our study found anaemia to be highly prevalent among patients with ESRD on MHD with iron deficiency being the predominant type. Factors such as having more than one comorbidities and a low transferrin saturation were significantly associated with anaemia. Conversely, education beyond primary level, duration of dialysis therapy beyond one year and permanent vascular access were shown to be protective against anaemia in these patients.

We therefore recommend that; strategies be put forward to address the above modifiable factors in order to help prevent anaemia in ESRD patients on MHD. Furthermore, routine screening of haemoglobin level and iron profile (transferrin saturation) should be promoted for early diagnosis and appropriate treatment of anaemia and iron deficiency in these patients.

\section{Conflict of Interest}

Authors declare no conflict of interest in this work.

\section{Contribution from Authors}

PJ, SM and MJ conceived the study, collected data and performed statistical analysis. JI proofread and re-wrote the manuscript in a more concise and succinct manner. FF, CP and KA reviewed the manuscript and provided useful inputs.

\section{Acknowledgements}

We thank the Department of Internal Medicine and the Renal Research Group at MUHAS for providing us with resources and protected time that enabled us to complete this manuscript.

\section{References}

1. Jhamb M, Weisbord SD, Steel JL, Unruh M (2008) Fatigue in patients receiving maintenance dialysis: a review of definitions, measures, and contributing factors. Am J Kidney Dis 52: 353-365.

2. Makubi A, Hage C, Lwakatare J, Mmbando B, Kisenge P, et al. (2015) Prevalence and prognostic implications of anaemia and iron deficiency in Tanzanian patients with heart failure. Heart 101: 592599.

3. de Oliveira MCC, Ammirati AL, Andreolli MC, Nadalleto MAJ, Barros CBS, et al. (2016) Anaemia em pacientes submetidos à diálise peritoneal ambulatorial: prevalência e fatores associados. J Bras Nefrol 38: 76-81.

4. Shibiru T, Gudina EK, Habte B, Deribew A, Agonafer T (2013) Survival patterns of patients on maintenance hemodialysis for end stage renal disease in Ethiopia: summary of 91 cases. BMC Nephrol 14: 127.

5. Kaze FF, Kengne AP, Mambap AT, Halle MP, Mbanya D, et al. (2015) Anaemia in patients on chronic hemodialysis in Cameroon: prevalence, characteristics and management in low resources setting. Afr Health Sci 15: 253-260.

6. White SL, Chadban SJ, Jan S, Chapman JR, Cass A (2008) How can we achieve global equity in provision of renal replacement therapy? Bull World Health Organ 86: 229-237.

7. Anees M, Mumtaz A, Ibrahim M, Shaheen SM, Asghar A (2010) Effect of anaemia and hyperhomocysteinemia on mortality of patients on hemodialysis. Iran J Kidney Dis 4: 60-65.

8. Edmund G, Lowrie MD, Martin R, Pollak MD (2017) Anaemia in Patients with Chronic Renal Failure and in Patients undergoing Chronic Hemodialysis. KTDA. 
9. Afshar R, Sanavi S, Salimi J, Ahmadzadeh M (2010) Hematological profile of chronic kidney disease (CKD) patients in Iran, in predialysis stages and after initiation of hemodialysis. Saudi J Kidney Dis Transpl 21: 368-371.

10. Pancha Mbouemboue O, Danbe OD, Tangyi Tamanji M, Ngoufack JO (2016) Frequency of Specific Cardiovascular Disease Risk Factors among Cameroonian Patients on Dialysis: The Cases of Anaemia, Inflammation, Phosphate, and Calcium. Cardiol Res Pract 2016: 5031927.

11. Soohoo M, Ahmadi SF, Qader H, Streja E, Obi Y, et al. (2017) Association of serum Vitamin B12 and folate with mortality in incident hemodialysis patients. Nephrol Dial Transplant 32: 10241032.

12. Clase CM, Ki V, Holden RM (2013) Water-soluble vitamins in people with low glomerular filtration rate or on dialysis: a review. Semin Dial 26: 546-567.

13. Hayat A, Haria D, Salifu MO (2008) Erythropoietin stimulating agents in the management of anaemia of chronic kidney disease. Patient Prefer Adherence 2: 195-200.

14. Besarab A, Frinak S, Yee J (1999) An indistinct balance: the safety and efficacy of parenteral iron therapy. J Am Soc Nephrol 10: 20292043.

15. Malyszko J, Malyszko JS, Pawlak K, Mysliwiec M (2006) Hepcidin, iron status, and renal function in chronic renal failure, kidney transplantation, and hemodialysis. Am J Hematol 81: 832-837.

16. Saeed F, Kousar N, Sinnakirouchenan R, Ramalingam VS, Johnson PB, et al. (2011) Blood Loss through AV Fistula: A Case Report and Literature Review. Int J Nephrol 2011: 350870.

17. Viana MB (2011) Anaemia and infection: a complex relationship. Rev Bras Hematol Hemoter 33: 90-92.

18. Kaze FF, Kengne AP, Magatsing CT, Halle MP, Yiagnigni E, et al. (2016) Prevalence and Determinants of Chronic Kidney Disease among Hypertensive Cameroonians according to Three Common Estimators of the Glomerular Filtration Rate. J Clin Hypertens (Greenwich) 18: 408-414.

19. Piccolli AP, Nascimento MMD, Riella MC (2017) Prevalence of chronic kidney disease in a population in southern Brazil (Pro-Renal Study). J Bras Nefrol 39: 384-390.

20. Reynolds K, Gu D, Chen J, Tang X, Yau CL, et al. (2008) Alcohol consumption and the risk of end-stage renal disease among Chinese men. Kidney Int 73: 870-876.

21. Kao WH, Puddey IB, Boland LL, Watson RL, Brancati FL (2001) Alcohol consumption and the risk of type 2 diabetes mellitus: atherosclerosis risk in communities study. Am J Epidemiol 154: 748-757.

22. Matos CM, Silva LF, D'Avila Melo NA, Kuwano AY, Kuwano AN, et al. (2013) Prevalence and Management of Anaemia in hemodialysis patients in a Brazilian population of predominantly African descent. Int J Artif Organs 36: 640-649.
23. O'Mara NB (2008) Anaemia in Patients with Chronic Kidney Disease. Diabetes Spectr 21: 12-19.

24. Ryu SR, Park SK, Jung JY, Kim YH, Oh YK, et al. (2017) The Prevalence and Management of Anaemia in Chronic Kidney Disease Patients: Result from the Korean Cohort Study for Outcomes in Patients with Chronic Kidney Disease (KNOW-CKD). J Korean Med Sci 32: 249-256.

25. Stauffer ME, Fan T (2014) Prevalence of Anaemia in Chronic Kidney Disease in the United States. PLoS One 9: e84943.

26. Fishbane S, Pollack S, Feldman HI, Joffe MM (2009) Iron indices in chronic kidney disease in the National Health and Nutritional Examination Survey 1988-2004. Clin J Am Soc Nephrol 4: 57-61.

27. Agarwal R (2017) Iron deficiency anaemia in chronic kidney disease: Uncertainties and cautions. Hemodial Int 21: S78-S82.

28. Belonje AM, Voors AA, van der Meer P, van Gilst WH, Jaarsma $T$, et al. (2010) Endogenous erythropoietin and outcome in heart failure. Circulation 121: 245-251.

29. Babitt JL, Lin HY (2012) Mechanisms of anaemia in CKD. J Am Soc Nephrol 23: 1631-1634.

30. Peters PJ, Moore DM, Mermin J, Brooks JT, Downing R, et al. (2008) Antiretroviral therapy improves renal function among HIV-infected Ugandans. Kidney Int 74: 925-929.

31. Kwaan HC (2011) Infection and Anemia. Curr Drug Targets Infect Disord 11: 40-44.

32. Roberts TL, Obrador GT, St Peter WL, Pereira BJ, Collins AJ (2004) Relationship among catheter insertions, vascular access infections, and anaemia management in hemodialysis patients. Kidney Int 66: 2429-2436.

33. McClellan W, Aronoff SL, Bolton WK, Hood S, Lorber DL, et al. (2004) The prevalence of anaemia in patients with chronic kidney disease. Curr Med Res Opin 20: 1501-1510.

34. Nelado AM, Mahlangu JN, Wazir B, Duarte R, Paget G, et al. (2019) Ethnic prevalence of anaemia and predictors of anaemia among chronic disease patients at a tertiary medical hospital in Johannessburg, South Africa. Int J Nephrol Renovasc Dis 12: 19-32.

35. Hodges VM, Rainey S, Lappin TR, Maxwell AP (2007) Pathophysiology of anaemia and erythrocytosis. Crit Rev Oncol Hematol 64: 139-158.

36. Al-Khoury S, Afzali B, Shah N, Thomas S, Gusbeth-Tatomir P, et al. (2007) Diabetes, kidney disease and anaemia: time to tackle a troublesome triad? Int J Clin Pract 61: 281-289.

37. Goncalves EA, Andreoli MC, Watanabe R, Freitas MC, Pedrosa $A C$, et al. (2004) Effect of temporary catheter and late referral on hospitalization and mortality during the first year of hemodialysis treatment. Artif Organs 28: 1043-1049.

38. Nassar GM, Ayus JC (2001) Infectious complications of the hemodialysis access. Kidney Int 60: 1-13.

39. Singh AK (2008) Anaemia of Chronic Kidney Disease. Clin J Am Soc Nephrol 3: 3-6. 